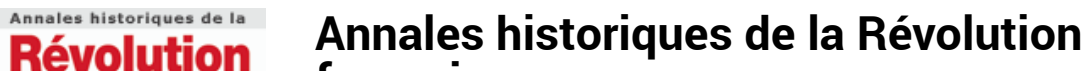

française française

325 | juillet-septembre 2001

Varia

\section{Esclavage, résistances et abolitions}

\section{Claude Mazauric}

\section{OpenEdition}

Journals

Édition électronique

URL : https://journals.openedition.org/ahrf/1127

DOI : 10.4000/ahrf.1127

ISSN : 1952-403X

Éditeur :

Armand Colin, Société des études robespierristes

Édition imprimée

Date de publication : 1 septembre 2001

Pagination : 121-122

ISSN : 0003-4436

\section{Référence électronique}

Claude Mazauric, "Esclavage, résistances et abolitions », Annales historiques de la Révolution française

[En ligne], 325 I juillet-septembre 2001, mis en ligne le 10 avril 2006, consulté le 23 avril 2022. URL http://journals.openedition.org/ahrf/1127 ; DOl : https://doi.org/10.4000/ahrf.1127

Ce document a été généré automatiquement le 23 avril 2022.

Tous droits réservés 


\title{
Esclavage, résistances et abolitions
}

\author{
Claude Mazauric
}

\section{RÉFÉRENCE}

Esclavage, résistances et abolitions, Paris, Éditions du C.T.H.S., 1999, 575 pages. Actes (partiels) du $123^{e}$ Congrès des Sociétés historiques et scientifiques, Fort-de-FranceSchoelcher, 1998, publiés sous la direction de Marcel Dorigny.

1 Dans cet excellent recueil regroupant une part importante des communications présentées en 1998 pour le cent cinquantième anniversaire de l'abolition de l'esclavage dans les colonies françaises à l'occasion du congrès réuni spécialement en Martinique puis en Guadeloupe, on trouvera la plupart des études de caractère historique ou ethnographique, consacrées à l'histoire des esclaves dans la plantation, à leurs luttes, aux procédures conduisant à l'abolition par le décret du 27 avril 1848 et à ses suites: c'est dire que ce livre est de portée considérable. Non qu'il traite exhaustivement de toutes les questions possibles; Marcel Dorigny dans une présentation maîtrisée et roborative, l'annonce sans ambiguïté: sur la quarantaine de communications réunies, aucune n'aborde directement la question du rétablissement de l'esclavage colonial en 1802 sous la pression du lobby colonial - cette authentique contre-révolution! - ni non plus l'histoire de l'insurrection de Saint-Domingue et à sa suite, l'histoire de la République de Haïti, comme on aurait dû et pu s'y attendre... Tout en prenant acte de ces lacunes, il convient simultanément de souligner l'exceptionnelle utilité de ce qui nous est offert. En sorte que si l'histoire terrible de ce que furent la traite, la déportation des Africain(e)s aux Amériques et l'esclavage productif dans les plantations ou domestique chez les maitres, ne se trouve pas enseignée dans les universités ou à l'occasion de travaux collectifs dans les établissements du second degré, personne ne pourra dire qu'il ne disposait pas de quelques moyens ou de travaux récents lui permettant de consacrer une part de ses moyens pédagogiques à ce qui demeure comme l'énorme tache imprimée sur notre histoire moderne. 
2 Sept communications relèvent de l'étude de la société coloniale; dans cet ensemble, on retiendra en particulier le beau texte de Michèle Duchet sur «le héros noir» (le «marron») et l'accent très nouveau mis sur la place des femmes esclaves (Marie Polderman, Jocelyne Jacquot). La bataille menée par les abolitionnistes dans les métropoles et les résistances qu'ils ont rencontrées, donne lieu à six communications (le cas du Havre fait l'objet des remarquables mises au point de Lucie Maquerlot et d'ÉricSaunier); on verra avec intérêt le différentiel des comportements entre France et Angleterre avec l'étude de F.Limare. Cinq communications balisent le moment insurrectionnel des esclaves en Guadeloupe (Abénon, Bélénus) ou à Saint-Domingue (Fl.Gauthier) tandis que Claude Wanquet fait le point sur la première abolition et les obstacles qu'elle rencontra immédiatement dans son application. La seconde vie de l'esclavage colonial, si l'on ose dire, de 1802 à 1848, fait l'objet de très fortes études parmi lesquelles se remarquent celle de Pascale Cornuel sur la communauté de Mana en Guyane de 1836 à 1846 ou celle de Léo Élisabeth sur la rémunération du travail «libre». L'observation comparée des autres processus d'abolition, à Cuba avec AlainYacou (Cuba où le marronnage fut considérable au point de construire une contre-société libérée à proximité de la société coloniale, fait de grande portée historique pour la suite...), à Porto-Rico après la révolution de Saint-Domingue avec la longue étude de Juan Gonzales-Mendoza, aux États-Unis à propos desquels ClaudeFolhen fait magistralement le point de la question: une abolition qui s'est traduite immédiatement et durablement par l'aggravation drastique des conditions de vie des anciens esclaves comme s'il avait fallu le leur faire payer! Trois communications sur le «travail_libre» et la question des suites sociales de l'abolition et neuf consacrées à la mémoire, active, reconstruite ou spontanée de l'esclavage, parmi lesquelles se signale l'étude consacrée par Dominique Delhaine à l'œuvre d'Édouard Glissant, achèvent ce recueil dont on mesure aisément la richesse. Un index des noms propres facilite grandement la consultation de l'ensemble, au demeurant très soigneusement édité et référencé.

3 La très belle introduction de J.-L. Bonniol insiste sur cette «rémanence des stigmates» dans notre histoire contemporaine que produisent la généalogie, le préjugé, la mémoire entretenue et reconstruite qui trouve sa visibilité dans ; J.-L. Bonniol évoque la nécessité de connaître et de comprendre cette «histoire_du_ressentiment», qui renvoie assurément à son entretien (utile? fondateur?) dans la culture, la littérature et la poésie ici particulièrement riches, la musique et les arts populaires, la politique... Mais peut-on ne remettre en question que le jeu de la mémoire dans cette «perduration»? L'histoire ici doit faire intervenir ce que furent les politiques métropolitaines post-abolitionnistes: à qui la terre? Comment le travail? Où les équipements? Quand l'égalité des droits sociaux et culturels? Entre la violence insupportable de l'exemple américain, la jungle sociale du Brésil et l'assistanat présent et d'ailleurs tard venu dans les Antilles française et à la Réunion, on cherchera en vain, sinon à Cuba pour une part ou à la Jamaïque dans ce cas particulier, un moment où les anciens dominants auront assumé de manière réparatrice, le crime antérieurement accompli.

4 Présent aux travaux de ce 128e congrès en 1998, j'y ai souvent éprouvé le sentiment étrange (et détestable) que la puissance coloniale d'hier, mon propre pays, après avoir tant de fois et si longtemps justifié l'esclavage, venait encore en ces lieux apporter la commémoration de l'abolition comme elle y avait autrefois importé l'esclavage, avec suffisance et bonne conscience. Heureusement, le recueil publié des Actes est d'un 
apport tel qu'il permettra d'en effacer le souvenir. Grâces en soient rendues à MarcelDorigny et aux éditeurs. 